\title{
THE ARCHIVES IN THE CONTOURS OF A KNOWLEDGE SOCIETY
}

\author{
Endre Kiss
}

While then the basic idea of the archiving keeps up today its relativistic character, the electronic archiving reveals in the same context as an hopelessly constructive and productive entreprise. The PC has undoubtedly made bearable the original problematic of the archiving, if just not made it more harmonious. The so characteristically postmodern appearing idea of the archiving was born at the time preceding the PC and carried from the beginning the sign of a true paradox. This paradox always oscillated between the spectacular main impossibility and the technical feasibility of the archiving. Thus, the whole questioning about the principles of the archiving came back almost totally. The PC made the archiving possible in an effective and economical way, while it covered its own revolutionary acquisitions in a schell of the avowed new randomness. Every knowledge became now integrable, the PC removed "only" all the difficulties of the "physical" integration, did not however bring to the end the randomness of the process to be integrated and of the integration process. The PC even legitimized the idea that the technical integration must not necessarily go together with the conceptual integration. As a result, the archiving developed towards an encyclopedism of the contingency, while the great encyclopedia of the eighteenth century, despite its lexical structure, was interesting for its true knowledge integration. Here we become aware of the fact, that the philosophy (very largely conceived: the whole discipline of the philosophical) has until now little dealt with the knowledge as knowledge. The universal project of the archiving reveals further also all these conflicts and contradictions, that usually articulate between the mediatization and its use, as well as between the system and its accessibility. While the technology allows an unlimited access, the relations of the market economy may deliberately restrict this fundamental non limitation. It appears as further contradiction, that the belles lettres on the net are necessarily at the same time (still) personal and (already) functional-impersonal. Under these circumstances, it reveals as increasingly problematic, if the author intends, also on the waves of the new mediatization, to hold on to the traditional author's role. A further, no less wide contradiction is, that while the archiving of the knowledge arouses an unprecedented widespread memory, this capacity of memory, effectively not yet imaginable up to now, can be completely destroyed.

The archiving leads necessarily to the socialization of any knowledge. It is however a socialization carried out individually in a curious way. In possession of the present communication means, under the conditions of the present forms of life and on the basis of the structure of the present cultural needs, the situation generates, that every individual draws up individually his (her) mass culture. The archiving also socializes the knowledge on the way of innumerable individually so-

Journal of Globalization Studies, Vol. 10 No. 1, May 2019 19-26 DOI: $10.30884 / j o g s / 2019.01 .02$ 
cialized knowledge files. The so occurred category of the social becomes thus not only a new category of our years, but also a new category of a new type of the present.

Keywords: archive, world net, social change, democracy, Borges, Foucault, knowledge integration, post-modern mass culture, socialisation of knowledge.

The opportunities to 'archive' in the Worldnet and to create 'archives' of all possible kinds could hardly shock in the good sense an attentive reader. Meanwhile, it appears really difficult to assess this phenomenon since here we deal with a radical revolutionary change which the everyday consciousness, being exhausted and intellectually no longer receptive, can hardly comprehend in a proper way. It is about a strange trace left by new modern democracy since the permanently changing relations create quite natural obstacles for an adequate comprehension of content and abilities, that would be necessary for the perception of opportunities needed by modern democracy.

The process turned out to be too challenging to make one take a decision to subject a society to permanent and radical changes. It is also fascinating in a way that there are constantly introduced new technological-media innovations aimed at differentiation. And at present there is no sign that a coherent sociology capable to explain these permanent differentiation processes could emerge in the future. However, we can understand (even if there are not any objective confirmations for that) that for many people the reaction to these ongoing radical changes of cultural and social capital consists in the fact that the differences between separate social groups are apparently becoming more meaningful. ${ }^{2}$

The original idea of archiving may be treated as one of the first genuinely postmodern ideas (even if this description is itself far from being fixed). It emerged at the threshold of the 1960s and 1970s and may be denoted as a turning point. It came from Borges and Foucault who actually relied on each other's approaches and respectively, made each other widely famous. They rejected the archiving itself yet they made this within two clearly differing philosophies. The intellectual triumph of the issues of fundamental differences could hardly occur and immediately become characteristic for the intellectual development in the last third of the twentieth century. The impression is enhanced if to approach the issue from different sides: the knowledge-sociological and ideological analysis of many currently leading ideas is not profound enough and there still remain several fundamental terms whose meaning is too blurred and unclear.

Borges left the basic concept of archiving in an agreeable insecurity. This could be interpreted first, as the demonstration of an extreme relativity of any discourse building, i.e. of any possible differentiation of fields of knowledge, second, as the demonstration of the relativity which any knowledge is unable to eliminate, third, as a proof of the impossible integration of any knowledge, or of any archiving. Yet, on the other hand, this is also a proof of the fact, that knowledge in its essence can (paradoxically) be integrated if necessary, and still one can point out to the non-integrable knowledge which works as a single unity via several cultural methods already before the revolution 
in computing science. Another "collecting" version, which is centered on Borges himself, claims that archiving is impossible since it inevitably destructs individual elements of knowledge at certain moments of time when they are fixed.

However this impossibility directly generates the necessity and motivation of archiving. From all that, Michel Foucault by means of a strong simplification would draw the thesis of the universal and eternal arbitrariness of knowledge originating from the idea about a philosophical logic of differences and political power and then develop his own concept of archiving.

Here it is also worth pointing out that both these discordant with each other points of view crystallized before the triumph of personal computer, that is prior to the creation of electronic network. It means, that the current problematics of archiving roots back to the contradictory creation history, that is to strongly contradictory creation myths.

While the basic idea of archiving currently preserves its relativistic character, the electronic archiving is developed within the same context with any hopelessly constructive and productive sphere. The PC has undoubtedly made the major subject of archiving more comprehensible, or just made it more harmonious. It is especially valid with respect to Foucault, whose history of science quite liberally ignores the determinant scientific-integrating science of the nineteenth century (by the way he similary ignores the whole nineteenth century as well as Marx, Darwin or Freud) (Focault 1999). ${ }^{3}$ It is not a coincidence that niether the history of ideologies, nor historicism and hermeneutic sciences of culture and education are paid sufficient attention which mostly means that Focault believes that these disciplines could hardly contribute to the material foundations of the knowledge archiving.

Specifically, the postmodern idea of archiving emerged before the origin of PC and from the very beginning it appeared a true paradox. This paradox always oscillated between the spectacular impossibility of archiving and its technical feasibility. Thus, all questions concerning the principles of archiving remained almost totally unresolved.

Meanwhile, the impossible became possible in a quite unforeseen manner. The revolution in information technologies found its final and still existing manifestation in the PCs which pointed to the developmental path. The huge constructive way forward however, did not destroy completely the deconstructive moments. The PC made the archiving possible, effective and economically feasible; meanwhile, the revolutionary achievements in the sphere of PCs were still explained in terms of officially stated randomness.

Every type of knowledge became integrable now; but although the PC 'merely' removed all difficulties with 'physical' integration; however, it did not completely eliminate the interference of randomness into the process of integration as well as the random character of the integration process itself. The PC even legitimized the idea that the technical integration must not necessarily go together with conceptual integration. As a result, the archiving developed into encyclopedism of the contingency, while the eighteenth-century Great Encyclopedia was interesting just due to its genuine knowledge integration despite its lexical structure. 
A science, even a new science of knowledge, may be archived. However, if we intend to pursue this way, then we will confront an unexpected difficulty since we are unable to immediately give a complex and up-to-date definition of knowledge. Here we become aware of the fact, that until present philosophy (in a broad sense, the whole discipline of philosophical thinking) has hardly dealt with knowledge as such.

Today it is established that during the successive historical periods we dealt constantly with a concrete type of knowledge and always tacitly assumed that this concrete knowledge is generally identical to the knowledge. The moment of truth is hidden here. The knowledge has always been considered valid and true so the general problematics of knowledge has effectively dissappeared from the scope of theoretical, and thus, practical interest.

The universal archiving project also reveals all these conflicts and contradictions, that usually articulate between the mediatization and its use, as well as between the system and its accessibility. Also archiving reveals another contradiction - that while the technology allows an unlimited access, the market economy may deliberately restrict this fundamental non-limitation. Another contradiction consists in the fact that the belles lettres downloaded in the net are simultenously (still) personal and (already) functionally impersonal. Under these circumstances, it becomes increasingly problematic on the waves of the new mediatization for an author to preserve the traditional author's role. One more significant contradiction is that archiving of knowledge generates an unprecedentedly large-scale phenomenon of 'memory' and this capacity to remember, effectively not yet imaginable up to now, can be completely destroyed. ${ }^{4}$

The archiving leads necessarily to democratization and socialization of any knowledge. However, the democratization and socialization proceed independenly from each other and each in its own particular way. These processes are somehow similar to what is widely spread today in the field of the so-called mass culture. It turns out that under the conditions of the present forms of life and on the basis of the structure of contemporary cultural needs the currently existing communication means allows every individual to individually develop his (her) own mass culture. The archiving also democratizes and socializes the knowledge on the way of innumerable individual knowledge files. This democratization and socialization produces a new monadic world, in which every individual monad can potentially reproduce the whole range of the knowledge. Thus, the emerging category of the social becomes not just a new category of our times, but also a new category of a new type of the present.

However, this is not the last utopian dimension in the structure of archives. The technological basis of archiving may lead to socialization of the knowledge essentially independent of the power. ${ }^{5}$ Thereby, it puts again the old question. Is it possible that the interpretation of the definition of knowledge necessary for its structuration attributes again to the category of power? The archiving creates a powerless utopia in the history of knowledge. This possibility can, however, in an unnoticeable and unperceptable manner pass by in case the structuring interpretation exposes itself in the knowledge to the same extent as as social power. The archives might, therefore, become the overcoming of the power in the organization of knowledge or - dialectically - just a reproduction 
of power in this function. Thus, the archives can realize the utopia of a powerlessly organized knowledge or - dialectically - a new reproduction of the interpretative power distributing knowledge. This applies both to the potential realization of knowledge and to potential overcoming in the same form.

This can also be applied to the strange irregularity and even to the heterogenous situation when archiving as a utopia is completed, similarly as the discussion about to be/not to be, and also about the character and nature of the knowledge society which are still unresolved to the full. It seems a coincidence that just at the threshold of 20052006, Bill Gates starts a campaign to redefine the nature of knowledge, or of popular knowledge (Kiss 2006). With regard to the constant efforts to define the peculiar nature of public information and knowledge, Bill Gates's sudden theoretical enthusiasm has an explosive character. This happens because in terms of globalization and popular knowledge (to name only these two most important examples), the purely theoretical and purely practical interests can be separated from each other with the greatest difficulties. The major advantage of a profound theoretical insight is important for all those directly involved, both for the initiator and also for the mediator of the insight, so that the definition of information society has been the most practical matter from the very beginning. ${ }^{6}$ Thus, Bill Gates's grown criticism is not clear since his criticism has suddenly turned to the past and is based on the fact that the notions of 'information society', 'information age' and similar terms do not fit the developmental trend of recent decades. He also immediately points that information is a limited phenomenon and this is true since information, in fact, is no more but a formulation of data, facts and basic material knowledge. To develop this idea of his, Gates notes that knowledge is in certain respects 'deeper' than information. We can almost assess this as a symbol of the Microsoft-man who uses the German metaphysics as reference. According to Gates, the current success story of 'information democracy' has an easy explanation While Gates was occupied with making access to information available to everyone, ${ }^{7}$ the historic task was the accessibility of knowledge.

Here a person with superficial knowledge of Gates conception and having quite doubtful intentions would think, that Gates had an objective (not to be confused with intrinsic reasons) not to find the path to enhance efficiency of knowledge but to promote the Google Team to achieve success. This means that the distinction, so determinant for the definition of archiving, between knowledge and information has become clear to Bill Gates, yet it happened quite late. Such personification and coincidences in the development of the knowledge politics remind very strongly about the missing actors in this field. It became too clear, that such global social opportunities must not be left to market economy, or its privileged actors (Kiss 2004: 312-319). So we must study new facets of the relations between 'knowledge' and 'interest'.

The exact distinction between the meanings of knowledge and information is the most important basis both for the information society and for the knowledge society, and in general for the problematic of archiving. As to archiving itself, a comparison between the productive medium course and the practical medium course reveal the differences between information (as a statement referring to a subject of positive reality) and knowledge (as an organized and verified continuity of information, or statements). 
In the strict sense, the archival information would be stored, while in a enlarged sense, however, the process is a bit different. The principles of archiving contain - somewhat deliberately - the principles of knowledge creation and distrubution. On the other hand, - and the former chapters of an archive serve as examples - the archiving must manifest itself as knowledge and not as information. And although every concrete case of archiving can operate a concrete realization of a global perception of knowledge, the archives inevitably become objects demonstrating what knowledge really means. The archiving symbolizes, in a tangible way, how the diverse types of knowledge begin to merge with each other and mutually exchange. They grow, but again, they grow together. They develop a vertical structure, but at the same time their complexity increases as well. The existing knowledge remains in a state of constant comparison, so an individual must always deal with surrounding permanent offers of knowledge, through which the knowledge is realized only in the form of knowledge for an individual.

However, all this hardly affects the strange traditional aspect of knowledge and knowledge accumulation which is adequate for search of solution neither with the help of computer science, nor with school perceptions about politics, nor with the indebted states driven into the corner. If the existing laws of knowledge accumulation are to be preserved in their current state, their actual development is possible only if all the elements are 'true' and considered valid. The more complex and diverse types of knowledge are incorporated in each other, the stronger is the possibility that also wrong or inappropriate types of knowledge will be considered invalid and that can obviously lead the whole knowledge accumulation in the wrong directions.

This generates the whole methodological problematic of the mutual transformation of different types of knowledge. It may appear surprising at the first glance that the mutual transformation of various types of knowledge is predominantly unconscious, it is a 'tacit' process which can very successfully unfold in practice even if it can hardly be described 'from outside' via theoretical-methodological means. ${ }^{8}$ Despite all these difficulties, one can hardly doubt that the previously mentioned truth, i.e. the real validity of various modules of knowledge, has been and remains an indispensable prerequisite of the truth and of value of the whole accumulated knowledge. As a result, it remains the sober truth, that the true knowledge cannot be substituted for mediatization and medial transformation. We must permanently work and struggle for the true knowledge.

This 'unconscious' sting of the higher knowledge accumulation and integration requires to consider the transfer of knowledge or the ability to transfer knowledge not as an overall mediatization. Here we suggest defining the ability to transfer knowledge as the foundation for the formation of higher and more complex forms of knowledge.

The distinction between 'dead' and 'living', 'old' and 'new' knowledge remains a weapon of the cautious school-level politicians from the indebted countries. The true nature of knowledge relativizes any relativization of the true knowledge definition. The true knowledge is an unlimited integration and unconscious merging of compatible types of knowledge with each other. So the omnipotent 'market' can only provisionally define which types of knowledge it will need in the future. In this respect, we consider the former state and party leader Nicolae Ceausescu as the true spokesman of the market 
economy, since already in the 1970s he knew quite exactly which types of knowledge the world market would need in the future and so he directed the Romanian youth's minds in professional schools teaching lathe operators, metal-workers and electricians. However, shortly afterwards under the impact of transforming world market the Romanian economy collapsed which also meant that the market had failed to exactly predict which types of knowledge, which elements and which synergetics of knowledge modules would appear really progressive and forward-looking for the society.

The conventional difficulties associated with relevant and competitive inclination to knowledge can be removed through further forms of organization, as well as through the networks or various alternative teambuilding practical courses. These forms efficiently promote the qualitative accumulation of knowledge. If we investigate this positive difference a bit closer, then we may realize that the gradually increasing performance occurs to a small degree due to the increase of positive knowledge capacity of a team; while for the most part, it comes from the better differentiation of the inner division of labor for the participants. There is no increase in performance in a direct sense because the network 'knows more' than the parties involved. The network can better and systematically reveal the undiscovered errors, suggest a lot of problems for further discussions, etc... It can better correct errors and solve problems than an individual.

Besides, even a whole team cannot perform any miracle. The knowledge cannot be replaced or reduced. What can only help is the PCs and archives...

\section{NOTES}

${ }^{1}$ Here it is obviously a reference to the imperative development of competence for modern democracy whose components have mostly an intellectual nature and thus are inseparably linked with 'knowledge'.

${ }^{2}$ Finally, it is obvious that it is not approriate to consider every advance as a factor increasing social differences.

${ }^{3}$ See Michel Foucault, Die Ordnung der Dinge. Frankfurt am Main 1999. It is amazing with what philosophical respect the scientific community adopts the conception of the rewritten history of science, thus, deliberately leaving aside the fateful events of the nineteenth century.

${ }^{4}$ However, there emerge two relevant moments here. On the one hand, the unprecedentedly global character of archives simply reminds of unprecedented global needs. On the other hand, archives appear sufficiently intact and just technically safe in these challenge situation.

${ }^{5}$ Now let us leave aside the historical-theoretical dimension, whether and to which extent 'the power' exclusively contributed to the formation of essential forms of knowledge. We do not share the radical conception within this problematic; nevertheless, we cannot but consider the theoretical problematic of the power here.

${ }^{6}$ Here we refer to the essentially new phenomenon, that the theoretical definition of information and knowledge society is, at the moment of its emergence, already conscious of particular interests of advantage and also other particular interests of disadvantage easy to perceive. However, this also means that the mediation way of a theoretical insight has become extremely short in the field of practical interests.

${ }^{7}$ We skip here the problematic of the taxes established for certain services.

${ }^{8}$ Practically this is manifested in the 'unconscious' character of knowledge accumulation and of the synergetic compensation of the individual knowledge elements, i.e. without our conscious participation and reflection. The unconscious knowledge is just a fascinating fact. 


\section{REFERENCES}

Foucault, M. 1999. Die Ordnung der Dinge. Suhrkamp: Frankfurt am Main. (First French edition 1966).

Kiss, E. 2004. Tudástársadalom, globalizáció, aktorok. (Knowledge Society, Globalization, Global Players). In Magyarország és a 21. század kihívásai az Európai Unióban. Komárom-VEAB, II. kötet (pp. 312-319).

Kiss, E. 2005. Über die verdoppelte Hegemonie in der Philosophie. Zur Symmetrie vom Neopositivismus/Neoliberalismus und Postmoderne. In Kaempfer, W., Neidhöfer H., and Ternes, B. (eds.), Die unsichtbare Macht. Neue Studien zu Liberalismus-Kapitalismus (pp. 203-217). Berlin: Geesthacht.

Kiss, E. 2006. Bill Gates kiosztja a tudást. Newsweek, Special Edition, December 2005 February 2006. E-Világ, Január, 7-8.

Kiss, E. 2007. Understanding Knowledge Society. In Hrachovec, H., Pichler, A. and Wang, J. (eds.), Philosophy of the Information Society. 30th International Wittgenstein Symposium. 5-11 August, 2007 (pp. 106-108). Kirchberg am Wechsel. 